\title{
Prevention of allograft heart valve failure in a rat model
}

\author{
Jean-Francois Légaré, $M D^{a, b}$ \\ David B. Ross, MDa \\ Thomas B. Issekutz, MD ${ }^{a, b, c}$ \\ Wendy Ruigrok, $\mathrm{BSc}^{\mathrm{a}}$ \\ Kimberley Creaser, $\mathrm{BSc}^{\mathrm{C}}$ \\ Greg M. Hirsch, MDa,b \\ Timothy D. G. Lee, PhD ${ }^{a, b, c}$
}

From the Departments of Surgery, Pathology, ${ }^{\mathrm{b}}$ and Microbiology and Immunology, ${ }^{\mathrm{c}}$ Dalhousie University, Halifax, Nova Scotia, Canada.

Supported by the Toronto Hospital for Sick Children Research Foundation.

Received for publication June 7, 2000; revisions requested Sept 5, 2000; revisions received Sept 28, 2000; accepted for publication Oct 16, 2000

Address for reprints: David Burns Ross, MD, IWK Grace Health Centre, 5850/5980 University Ave, Halifax, Nova Scotia, Canada, B3J 3G9 (E-mail: dross@iwkgrace.ns.ca)

J Thorac Cardiovasc Surg 2001;122:310-7

Copyright (C) 2001 by The American Association for Thoracic Surgery

0022-5223/2001 $\$ 35.00+0 \quad \mathbf{1 2 / 1 / 1 1 2 3 3 6}$

doi: $10.1067 / \mathrm{mtc} .2001 .112336$
Objective: Allograft heart valves are commonly used in cardiac surgery. Despite mounting evidence that these valves are immunogenic, leading to premature failure, current clinical practice does not attempt to minimize or control such a response. The objective of this study was to evaluate immune modulatory approaches to ameliorate allograft valve failure in a rat model.

Method: Aortic valve grafts were implanted infrarenally into Lewis rat recipients (n $=32$ ). There were 4 transplant groups: syngeneic grafts (Lewis to Lewis), untreated allografts (Brown Norway to Lewis), allograft recipients treated with cyclosporine (INN: ciclosporin) (10 mg/kg per day for 7 or 28 days), and allograft recipients treated with anti- $\alpha 4$ integrin and anti- $\beta 2$ integrin monoclonal antibodies for 7 days. At 7 and 28 days the valves were examined for structural integrity and cellular infiltration.

Results: Both cyclosporine and anti- $\alpha 4 / \beta 2$ integrin treatment resulted in significant reduction in leaflet infiltration by macrophages $\left(\mathrm{ED}^{+}\right)$, $\mathrm{T}$ cells $\left(\mathrm{CD}^{+}\right)$, and $\mathrm{CD} 8^{+}$ $\mathrm{T}$ cells at 7 days with preservation of structural integrity when compared with control allografts. Twenty-eight days after implantation, daily treatment with cyclosporine preserved leaflet structural integrity and inhibited cellular infiltration. However, a short course of cyclosporine ( 7 days) failed to prevent destruction of the valves at 28 days.

Conclusions: Immune modulatory approaches aimed at T-cell activation or trafficking decrease leaflet cellular infiltration and prevent allograft valve structural failure. However, short-course therapy does not appear to be sufficient and must be maintained to allow long-term preservation of leaflet structural integrity (28 days).

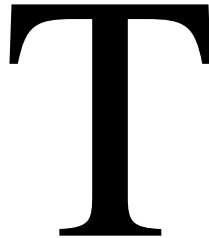

hirty-five years after the first cardiac valve replacements were undertaken, a perfect valve substitute has not been developed. Allograft heart valves (homografts) were introduced for aortic valve replacement in $1962^{1}$ and for reconstruction of the right ventricular outflow tract in $1966 .{ }^{2}$ Allograft valves have many advantages over commercially available mechanical and bioprosthetic valves: low transvalvular gradients, low rates of thromboembolism, and resistance to infection. ${ }^{3}$ They are used extensively for children, who are prone to rapid calcification of xenograft valves and for whom warfarin treatment is difficult.

Despite these advantages, allografts do ultimately fail in the aortic position. In children aged less than 3 years, allograft failure may be as high as $70 \%$ with a mean replacement interval of 1.9 years after the original operation. ${ }^{4}$ Proposed causes of 
TABLE I. Experimental groups $(\mathbf{n}=32)$

\begin{tabular}{llllccc}
\hline Group & Recipient & Donor & Treatment & $\begin{array}{c}\text { No. } \\
\text { transplanted }\end{array}$ & $\begin{array}{c}\text { No. at } \\
\text { 7 days }\end{array}$ & $\begin{array}{c}\text { No. at } \\
\text { 28 days }\end{array}$ \\
\hline Syngeneic controls & Lewis & Lewis & None & 8 & 4 & 4 \\
Untreated allogeneic & Lewis & BN & None & 8 & 4 & 4 \\
Allogeneic + CAM & Lewis & BN & Anti- $\alpha 4 / \beta 2$ & 4 & 3 & - \\
Allogeneic + CyA & Lewis & BN & Daily CyA $\times 7$ days & 8 & 4 & 4 \\
Allogeneic + CyA & Lewis & BN & Daily CyA $\times 28$ days & 4 & - & 4 \\
\hline
\end{tabular}

The 5 groups of animals created and treatments received. BN, Brown Norway; CAM, cell adhesion molecule; CyA, cyclosporine.

this failure have included immune rejection. Donor-specific immune responses to fresh aortic valve grafts have been shown in animal models. ${ }^{5}$ Mixed lymphocyte cultures using spleen cells from allografted rodents have demonstrated a significant increase in stimulation, suggesting systemic activation of $\mathrm{CD}^{+} \mathrm{T}$ cells during the initial exposure to the allograft valve. Further, the frequency of cytotoxic T-lymphocyte precursors was significantly increased in the spleen of these animals. In human beings, some evidence supports similar cell-mediated responses to allografted valves. ${ }^{6,7}$ In particular, there is an accelerated peripheral T-cell response, specific to donor peripheral blood mononuclear cells, as demonstrated in recipients of valve grafts 10 days after implantation, with a peak response appearing on day 30 . In addition, allografts that undergo accelerated failure have shown evidence of associated T-cell infiltration. ${ }^{8}$

However, despite mounting evidence that aortic allografts are immunogenic and can elicit donor-specific immune responses, ${ }^{9-11}$ and more particularly T-cell responses, ${ }^{5-8}$ current clinical practice does not attempt to minimize or control such a response. Some clinicians have attempted to match valves for $\mathrm{ABO}$ blood group compatibility, but there is no evidence that this is beneficial. ${ }^{12}$ Currently, HLA matching is not being attempted in patients. Immunosuppressive or antiinflammatory agents have occasionally been tried, but no rigorous, prospective study has been performed. ${ }^{4}$

Evidence from animal models suggests that immunosuppressive regimens (cyclosporine [INN: ciclosporin]) may ameliorate humoral responses to valve allografts. However, no information has been presented regarding the structure of valve leaflets in such animals nor have any in situ descriptions of the cellular responses been presented. ${ }^{13} \mathrm{We}^{14}$ have recently shown that $\mathrm{CD}^{+} / \mathrm{CD}^{+}$cytotoxic $\mathrm{T}$ lymphocytes infiltrate allogeneic valve leaflets early after implantation and that this is associated with structural failure and destruction of valve leaflets. This infiltration was confirmed by demonstrating that cellular infiltration and valve destruction do not occur in the absence of a functional T-cell compartment (nude rat recipients). ${ }^{14}$

T-lymphocyte trafficking to transplanted organs remains poorly studied, with most of the work having been per- formed in models of acute and chronic inflammation. On the basis of these models, lymphocytes are believed to infiltrate organs by adhesion to vascular endothelial cells using cell adhesion molecules (CAMs), with subsequent transmigration through the endothelium. ${ }^{15}$ Alpha $4(\alpha 4)$ and beta 2 ( $\beta 2)$ integrin molecules appear particularly important for the trafficking of $\mathrm{T}$ lymphocytes because the expression of their respective ligands has been shown to be up-regulated on vascular endothelial and parenchymal cells of transplanted organs, including valve grafts, early in the rejection process. ${ }^{15-17}$ The identification of specific CAMs necessary for mononuclear infiltration of allotransplanted valve leaflets would provide important mechanistic information and offer the potential for therapeutic applications.

The objectives of this study were (1) to evaluate the role of a classic T-cell immunosuppressant (cyclosporine) and (2) to identify mechanisms by which these T cells infiltrate leaflets lead to allograft valve failure in a rat model.

\section{Materials and Methods \\ Animals}

Inbred male Brown Norway $\left(\mathrm{RT} 1 . \mathrm{A}^{\mathrm{n}}\right)$ and Lewis $\left(\mathrm{RT} 1 . \mathrm{A}^{\mathrm{l}}\right)$ rats weighing 250 to $350 \mathrm{~g}$ were purchased from Harlan Sprague Dawley, Inc (Indianapolis, Ind) and housed in the Medical Sciences animal care facility with food and water ad libitum for 1 week before experimentation. The animals were handled in accordance with the guidelines of the Canadian Council of Animal Care. ${ }^{18}$

\section{Aortic Valve Allograft Implantation}

Transplantation of aortic valve allografts was performed as first described by Yankah, Wottge, and Muller-Ruchholtz. ${ }^{19}$ An intraperitoneal injection of sodium pentobarbital, $65 \mathrm{mg} / \mathrm{kg}$, was used to anesthetize the rats.

Donor operation. A midline upper abdominal incision was made and extended as a median sternotomy. The aortic valve containing some myocardium and approximately $8 \mathrm{~mm}$ of ascending aorta was dissected free, and the coronary ostia were ligated with 9-0 nylon sutures (Sharpoint, Reading, Pa). The graft was then rinsed with cold isotonic saline solution. Both the donor and recipient operations were performed with a Weck OM-1206 mounted operating microscope (Weck Closure Systems, Research Triangle Park, NC). 


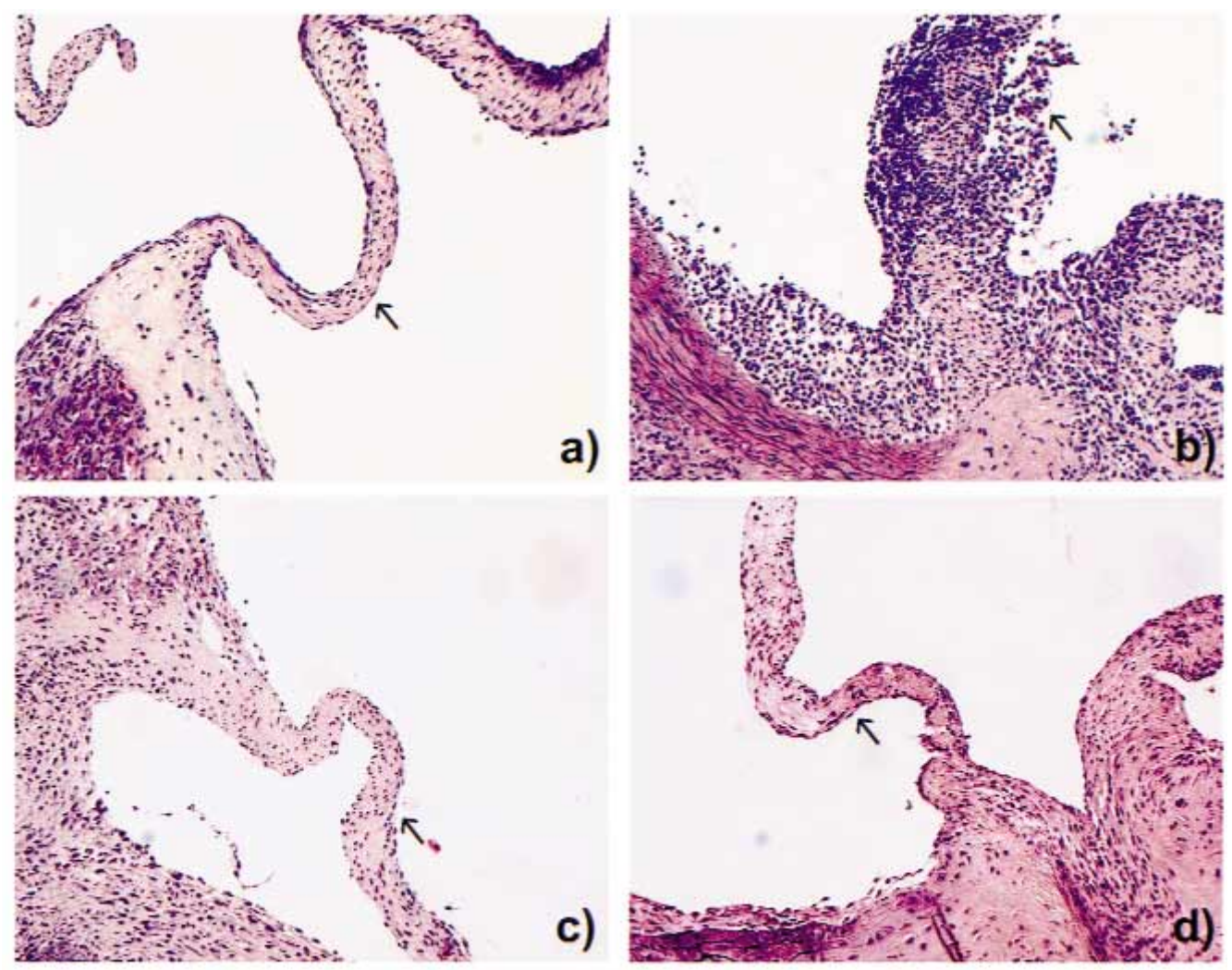

Figure 1. Photomicrographs of valve leaflets 7 days after implantation in syngeneic (Lewis to Lewis) (a), untreated allograft recipients (Brown Norway to Lewis) (b), allograft recipients treated with anti- $\alpha 4 / \beta 2$ monoclonal antibody (c), and allograft recipients treated with cyclosporine (d). Arrow indicates leaflet. (Original magnification $\times$ 200.)

Recipient operation. A midline laparotomy was performed, the bowel eviscerated to the right, and the abdominal aorta exposed. The aorta was mobilized from the level of the renal artery to the aortic bifurcation and divided between clamps. The fresh aortic valve allograft was then anastomosed between the stumps of the recipient aorta with interrupted 9-0 nylon sutures (Sharpoint), being flushed intermittently with heparinized saline solution. Once hemostasis was secured, the abdominal contents were returned into the peritoneal cavity and the wound was closed in layers. Strain combinations for experimentation consisted of syngeneic controls (Lewis to Lewis; $\mathrm{n}$ $=8$ ), untreated allograft recipients (Brown Norway to Lewis; $\mathrm{n}=8$ ), allograft recipients treated with cyclosporine $(n=12)$, and allograft recipients treated with anti- $\alpha 4 / \beta 2$ monoclonal antibody $(\mathrm{mAb})(\mathrm{n}=$ 4). A single animal died after the operation and was part of the anti$\alpha 4 / \beta 2$ group. Table 1 illustrates the various groups of animals created and the treatment received.

\section{Immune Modulation of Recipients}

Cyclosporine (Sandoz Canada, Dorval, Quebec, Canada), dosage $10 \mathrm{mg} / \mathrm{kg}$ per day diluted in olive oil, was given by gavage feeding as previously reported. ${ }^{13,20}$ Random serum cyclosporine levels measured several days after valve implantation were obtained by radioimmunoassay (DiaSorin Cyclo-Trac, QEII HSC; DiaSorin, Inc, Stillwater, Minn) in 2 animals and shown to be 1450 and 1615 $\mu \mathrm{g} / \mathrm{L}$. CAM blockade consisted of the mAb TA-2 (immunoglobulin [ $\mathrm{Ig}$ ] G1 blocking mAb specific for $\alpha 4$ integrin subunit; $3 \mathrm{mg}$ intravenously) and the mAb WT.3 (IgG1 blocking mAb specific for CD18 or $\beta 2 ; 3 \mathrm{mg}$ intravenously) given on day 0 and repeated on day 4 after valve implantation. ${ }^{21,22}$ Dosing was based on previous studies documenting antibody serum levels and efficacy of treatment at blocking cellular trafficking. ${ }^{23,24}$ The presence of antibody in serum was confirmed by flow cytometry (fluorescenceactivated cell sorter staining). Flow cytometry was performed on a BD FACScan with Lysis II software (Becton Dickinson, Franklin Lakes, NJ).

\section{Tissue Analysis}

Grafts were harvested for histologic examination at 7 and 28 days and immersion-fixed ( $10 \%$ formaldehyde) at $4^{\circ} \mathrm{C}$ for 12 hours. Grafts were then paraffin-embedded, and $5-\mu \mathrm{m}$ sections were cut serially for histologic and immunocytochemical examinations.

Tissue sections were stained with hematoxylin and eosin (Harris hematoxylin) or Verhoeff elastin stain (hematoxylin 5\%, ferric chloride $10 \%$, and Lugol iodine). Tissue slides from each animal were then examined with a light microscope and images digitized and captured (JVC digital camera, model TK1070U; JVC Professional Products Company, Wayne, NJ). Morphometric analysis was carried out with Adobe Photoshop 


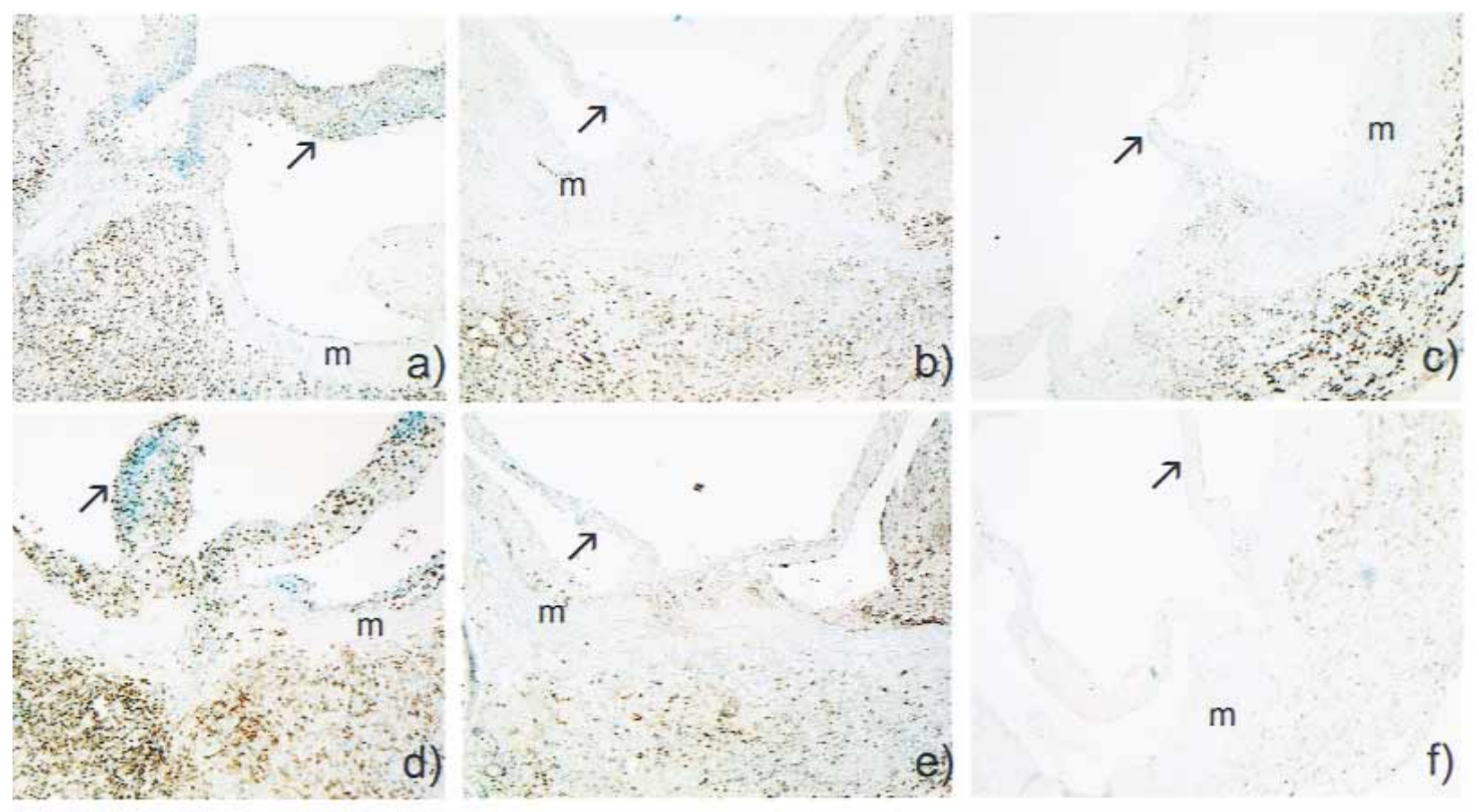

Figure 2. Photomicrographs of immunocytochemical staining 7 days after implantation in untreated allograft recipients (Brown Norway to Lewis) anti-ED1 (a) and anti-CD8 (d); allograft recipients treated with anti- $\alpha 4 / \beta 2$ monoclonal antibody anti-ED1 (b) and anti-CD8 (e); and allograft recipients treated with cyclosporine, anti-ED1 (c) and anti-CD8 (f), with a secondary immunoperoxidase reaction. Arrow indicates leaflet. (Original magnification $\times 200$.)

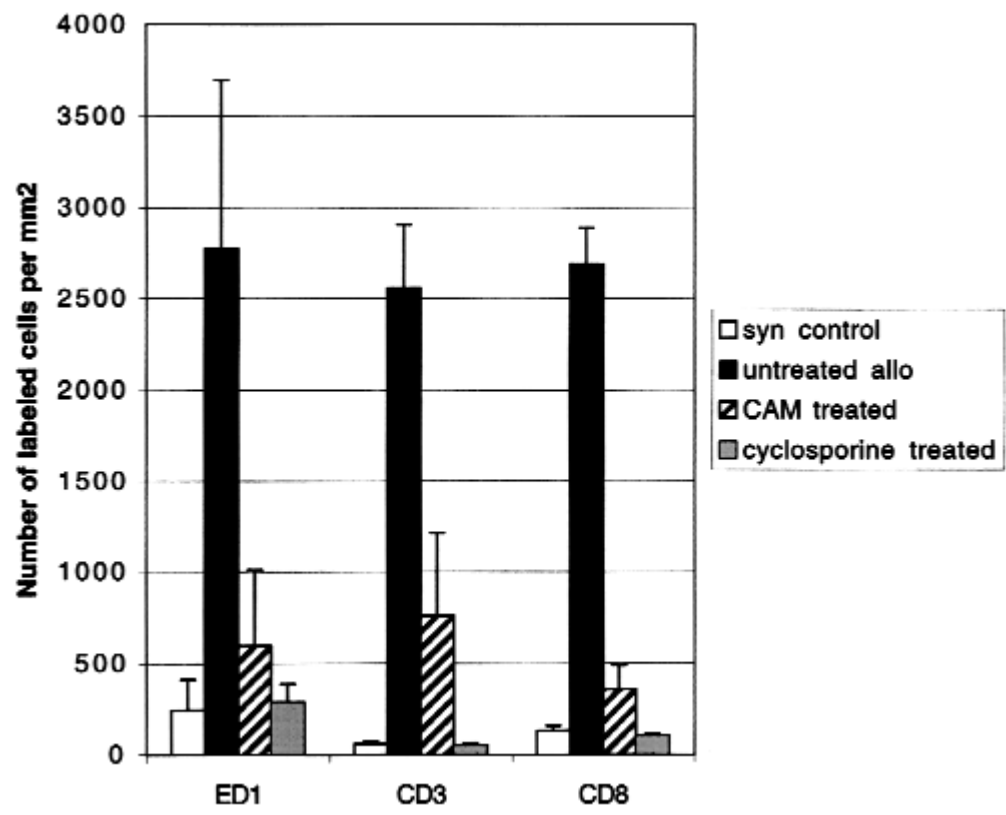

Figure 3. Graph comparing the number of immunolabeled cells per surface area present in leaflets 7 days after implantation in control syngeneic (Lewis to Lewis), untreated allograft recipients (Brown Norway to Lewis), allograft recipients treated with anti- $\alpha 4 / \beta 2$, and allograft recipients treated with cyclosporine. The antibodies used were anti-ED1, anti-CD3, and anti-CD8 monoclonal antibody and secondary immunoperoxidase reaction. Counts were expressed as number of cells per square millimeter of leaflet area. allo, Allogeneic; CAM, cell adhesion molecule; syn, syngeneic. 


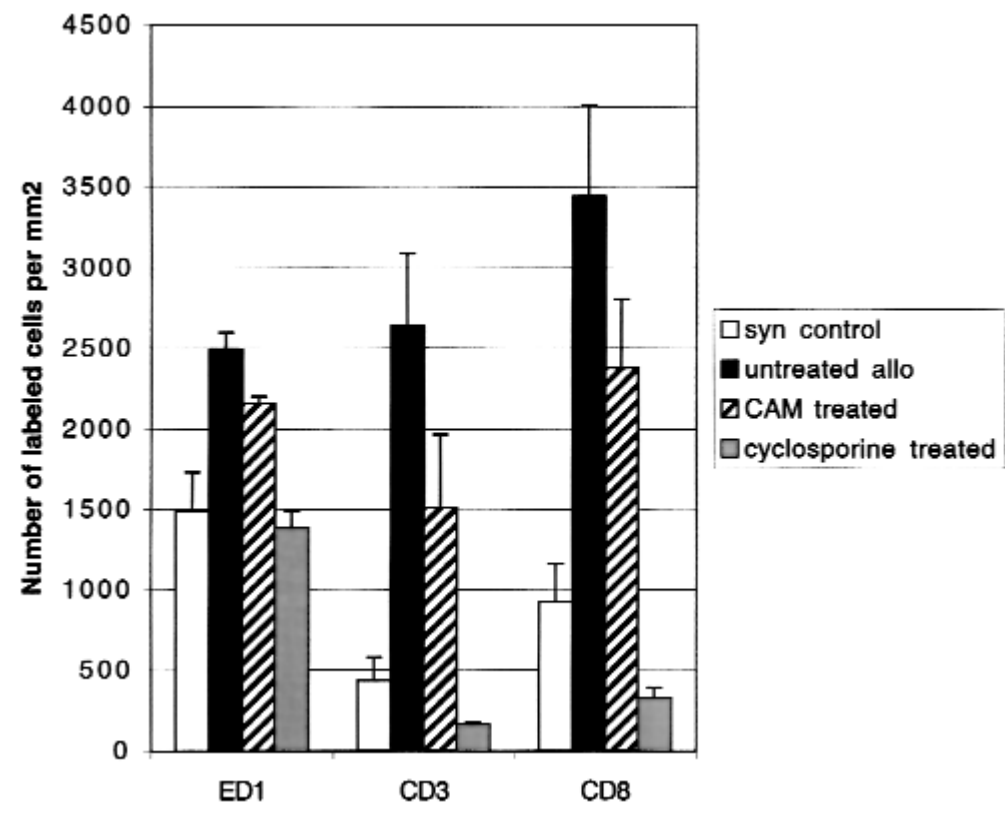

Figure 4. Graph comparing the number of immunolabeled cells per surface area present in the adventitia 7 days after implantation in control syngeneic (Lewis to Lewis), untreated allograft recipients (Brown Norway to Lewis), allograft recipients treated with anti- $\alpha 4 / \beta 2$, and allograft recipients treated with cyclosporine. The antibodies used were anti-ED1, anti-CD3, and anti-CD8 monoclonal antibody and secondary immunoperoxidase reaction. Counts were expressed as number of cells per square millimeter area of adventitia obtained from multiple sampled areas. allo, Allogeneic; CAM, cell adhesion molecule; syn, syngeneic.

(Microsoft, Inc, Redmond, Wash) and NIH Image analyzer software on a Power PC (G3, Apple Computer, Cupertino, Calif) to measure surface area (square micrometers) and cell counts per area. Leaflet cell density (number of labeled cells per area) was obtained from sampling of the entire leaflet area from representative tissue cross sections from each animal (area where leaflet cusps were visualized). Adventitial cell counts were obtained from the average cell density (number of labeled cells per area) of 4 representative areas of adventitia sampled at the $0,3,6$, and 9 o'clock positions from representative tissue cross sections from each animal.

\section{Immunohistochemistry}

After deparaffinization, endogenous peroxidase was quenched $(0.06 \%$ hydrogen peroxide/methanol), nonspecific staining was blocked with normal horse serum, and sections were subsequently incubated with primary $\mathrm{mAb}$ for 1 hour at $37^{\circ} \mathrm{C}$. The antibodies used were anti-ED1 (ED1; Cedarlane Laboratories, Hornby, Ontario, Canada) specific for monocyte/macrophage lineage cells, anti-CD3 (R73; Cedarlane Laboratories) specific for $\alpha \beta$ T-cell receptor positive bearing cells, and anti-CD8 (MRC OX-8; Cedarlane Laboratories) specific for a cell surface molecule present on $\mathrm{CD}^{+}$cytotoxic $\mathrm{T}$ lymphocytes. Sections were then washed in phosphate-buffered saline solution containing $1 \%$ bovine serum albumin (Sigma Chemical Company, St Louis, Mo) 3 times before incubation with biotinylated secondary antibody and labeling with peroxidase avidin/biotin complex using 3.3' diaminobenzidine as the chromogen (Vector Laboratories, Inc, Burlingame, Calif).

\section{Statistics}

The mean number of cells counted from histologic slides was obtained from 4 animals in each group. Data were reported as mean and standard error of the mean. Changes in cellular density were expressed as percent change between treated and untreated control animals with syngeneic density counts used as baseline values. Analysis of variance was used to evaluate groups consisting of syngeneic controls, untreated allografts, allografts treated with cyclosporine, and allografts treated with anti- $\alpha 4 / \beta 2$. The post hoc Fisher test of least significant difference was used to assess statistical significance with $P<.05$ being the limit of significance. An unpaired 2 -tailed Student $t$ test was used for simple comparisons to assess statistical significance with $P<.05$ being the limit of significance.

\section{Results}

Transplanted valve grafts were harvested and evaluated by light microscopy 7 days after implantation in syngeneic controls (Lewis to Lewis, $n=4$ ), untreated allograft recipients (Brown Norway to Lewis, $n=4$ ), allograft recipients treated with cyclosporine $(n=4)$, and allograft recipients treated with anti- $\alpha 4 / \beta 2(n=3)$. Syngeneic control aortic valve leaflets remained thin, cellular, and showed no evidence of immune infiltration into the leaflets (Figure 1, a). Allografted aortic valve leaflets exhibited significant mononuclear cell infiltration (Figure 1,b), as previously described, when compared with syngeneic controls. ${ }^{10,14}$ 

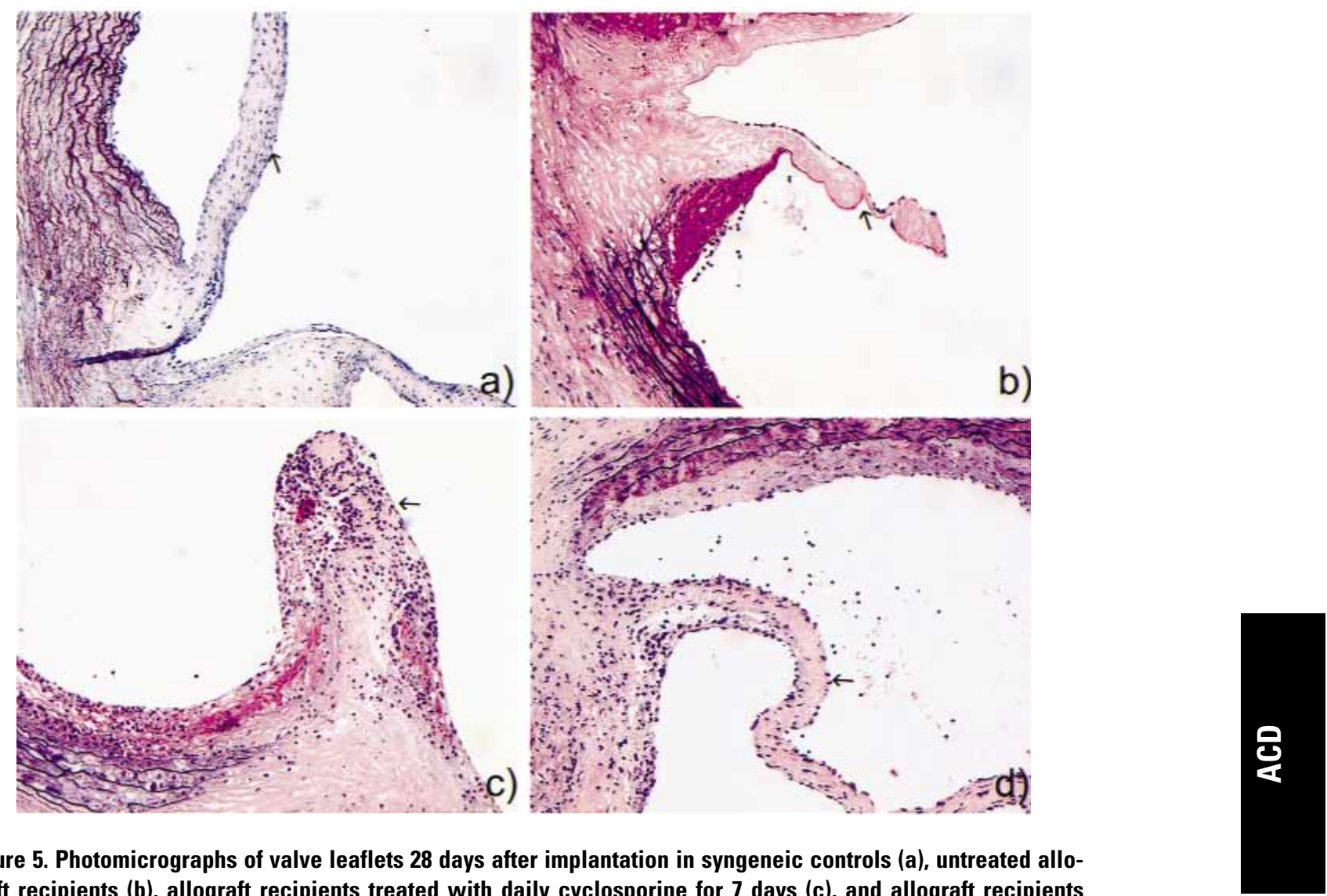

Figure 5. Photomicrographs of valve leaflets 28 days after implantation in syngeneic controls (a), untreated allograft recipients (b), allograft recipients treated with daily cyclosporine for 7 days (c), and allograft recipients treated with daily cyclosporine for $\mathbf{2 8}$ days (d). Arrow indicates leaflet. (Original magnification $\times \mathbf{2 0 0}$.).

Cyclosporine therapy resulted in significantly less mononuclear cell infiltration of both valve leaflets and adventitia with preservation of structural leaflet integrity at 7 days (Figure 1, $d$ ). Immunocytochemistry was used to quantitate and characterize the nature of immune infiltrating cells 7 days after implantation (Figures 2, 3, and 4). There was a 98\% $(P=.005)$ reduction in $\mathrm{ED} 1^{+}$cells, $100 \%(P \leq .001)$ reduction in $\mathrm{CD}^{+}$cells, and $100 \%(P \leq .001)$ reduction in $\mathrm{CD}^{+}$cells infiltrating leaflets. The adventitia showed a $100 \%(P \leq .001)$ reduction in $\mathrm{ED} 1^{+}$cells, $100 \%(P=.002)$ reduction in $\mathrm{CD}^{+}$cells, and $100 \%(P \leq .001)$ reduction in $\mathrm{CD} 8^{+}$cellular infiltration in allograft recipients treated with cyclosporine compared with untreated recipients.

Short-term therapy (7 days) versus daily therapy with cyclosporine was evaluated at 4 weeks and compared with results in syngeneic controls $(n=4)$ and untreated allografts $(\mathrm{n}=4)$. Daily therapy $(10 \mathrm{mg} / \mathrm{kg}$ per day $)$ with cyclosporine $(\mathrm{n}=4)$ (Figure 5, $d)$ inhibited leaflet infiltration by mononuclear cells and allowed preservation of leaflet structural integrity resulting in a normal appearing functional leaflet similar to that seen in syngeneic control animals (Figure 5, a). In contrast, animals that had received a 7-day course of cyclosporine and were evaluated at 28 days all showed evidence of leaflet destruction and complete loss of structural integrity $(n=4)$ (Figure 5,c), similar to what has previously been described in untreated animals (Figure 5, b). ${ }^{10,14}$

Having shown that $\mathrm{T}$ lymphocytes and monocytes/ macrophages significantly infiltrate allogeneic leaflets within 7 days after implantation, we proceeded to evaluate the mechanism by which these cells gained access to the implanted tissue. Anti- $\alpha 4 / \beta 2$ integrin blockade resulted in significant reduction in mononuclear cell infiltration (Figure 1,c), which was then confirmed by immunocytochemistry (Figures 2, 3, and 4). Anti- $\alpha 4 / \beta 2$ integrin $\mathrm{mAb}$ blockade resulted in $86 \%(P=.032)$ reduction in $\mathrm{ED} 1^{+}$ cells, $72 \%(P \leq .001)$ reduction in $\mathrm{CD}^{+}$cells, and $91 \%(P$ $\leq .001)$ reduction in $\mathrm{CD}^{+}$cells infiltrating leaflets. There was a $33 \%(P=.088)$ reduction in $\mathrm{ED} 1^{+}$cells, $51 \%$ $(P=.023)$ reduction in $\mathrm{CD}^{+}$cells, and $42 \%(P=.034)$ reduction in $\mathrm{CD}^{+}$cells infiltrating the adventitia of allograft recipients after this $\mathrm{mAb}$ blockade. 


\section{Discussion}

Contrary to solid organ transplantation, which requires immediate and lifelong immunosuppression, allograft heart valves remain clinically functional without immunosuppression for a number of years before failing. ${ }^{1}$ To date, no systematic attempt has been made to evaluate whether immunosuppression can lead to long-term survival of viable valve cellular elements in human beings or animals, despite increasing evidence that allograft heart valves in both animals and human beings are antigenic and result in significant donor-specific immune responses. ${ }^{5-11} \mathrm{We}^{14}$ have recently provided evidence that aortic valve graft failure in a rat model is immune mediated and associated with significant infiltration of the leaflet by $\mathrm{T}$ lymphocytes, more particularly $\mathrm{CD}^{+}$cytotoxic $\mathrm{T}$ lymphocytes. On the basis of that evidence, therapeutic strategies aimed at T-cell activation and/or infiltration were evaluated for their ability to prevent early leaflet infiltration, which has been associated with subsequent loss of stromal cells and eventual structural failure of the leaflet. ${ }^{14,25}$

In the present study, Lewis rats were treated with an immunosuppressive regimen consisting of oral cyclosporine $(10 \mathrm{mg} / \mathrm{kg}$ per day) aimed specifically at T-cell activation. This treatment is known to result in long-term survival of vascularized allogeneic heart and kidney grafts in the rat. ${ }^{26}$ We have shown that continuous cyclosporine treatment resulted in a significant reduction in macrophage $\left(\mathrm{ED} 1^{+}\right)$ and T-cell $\left(\mathrm{CD}^{+}, \mathrm{CD}^{+}\right)$infiltration of leaflets, in addition to a significant reduction in infiltrating $\mathrm{T}$ cells in the adventitia early after implantation. This treatment was very effective in preserving leaflet structural integrity.

The use of cyclosporine has been reported in a series of patients requiring fresh arterial homograft implantation for aortoiliac infection and was reported to cause few complications. ${ }^{27}$ However, few clinicians have treated allograft valve recipients with systemic immunosuppression for extended periods because of the potential morbidity associated with permanent immunosuppression. Yankah, Wottge, and Muller-Ruchholtz ${ }^{13}$ suggested that a short course of cyclosporine (14 days) could arrest allograft valve rejection on the basis of antibody responses. We therefore evaluated the potential benefit of a shortcourse treatment with cyclosporine around the time of maximal leaflet mononuclear infiltration (day 7) as compared with continuous daily cyclosporine. The present study is the first to clearly demonstrate that the histologic integrity of the leaflets is not preserved by a short course (7 days) of cyclosporine and that complete leaflet destruction had occurred at 28 days. In contrast, continuous daily cyclosporine treatment resulted in preserved leaflet structural integrity (similar to syngeneic grafts) with no signif- icant mononuclear infiltration for the entire duration of the study (28 days).

Taken together, these data provide strong evidence that early valve leaflet failure is immune mediated and dependent on T lymphocytes. Immunosuppression, which targets primarily T-lymphocyte activation and proliferation, is protective and maintains valve allograft structural integrity. These findings support our previously reported evidence that $\mathrm{T}$ lymphocytes mediate valve allograft failure. ${ }^{10,14}$

Little is known about the mechanisms by which important immune effector cells gain access to the transplanted tissues, including allograft valves. Leukocyte function-associated antigen-1 (LFA-1) $(\alpha L \beta 2)$, very late activation antigen-4 (VLA4) ( $\alpha 4 \beta 1)$, MAC-1 ( $\alpha \mathrm{M} \beta 2)$, and $\alpha \mathrm{X} \beta 2$ are integrin molecules composed of an $\alpha$ and $\beta$ subunit that are used by T cells and monocytes to infiltrate sites of inflammation. ${ }^{28}$ The ligands for these integrins are expressed by endothelial cells in response to injury and activation, such as transplantation, and include intercellular adhesion molecules 1 and 2 (ICAM- 1 and ICAM-2) and vascular cell adhesion molecule 1 (VCAM1). ${ }^{16,17}$ The importance of CAMs in facilitating organ allograft rejection is supported by studies that have attempted to block the interactions between CAMs and their ligands with $\mathrm{mAbs}^{29}$ or with soluble ligands. ${ }^{30}$ Blocking antibodies to certain CAMs have been well demonstrated to prolong graft survival of solid organ grafts such as heart and renal transplants. ${ }^{29,31}$

On the basis of the above information, a strategy of $\alpha 4$ and $\beta 2$ blockade was chosen for the current experiments and should have caused effective blockade of integrins known to be used by $\mathrm{T}$ cells and monocytes. This strategy resulted in significant reduction in monocyte/macrophage lineage cells $\left(\mathrm{ED}^{+}\right)$and $\mathrm{T}$ lymphocytes $\left(\mathrm{CD}^{+}, \mathrm{CD}^{+}\right)$in allogeneic leaflets 7 days after implantation as compared with untreated allografted recipients. ${ }^{10,14}$ In contrast, the same blockade was unable to reduce monocyte/macrophage infiltration of the adventitia of the graft and resulted in only moderate reduction in T-cell infiltration of the adventitia. These findings suggest different mechanisms of trafficking of effector cells to leaflet tissue versus the adventitia. CAMs may also have important co-stimulatory roles, which were not specifically assessed in this study. ${ }^{28}$ However, the half-life of anti$\alpha 4 / \beta 2 \mathrm{mAb}$ therapy is relatively short and requires repeated therapy such that no attempts were made to pursue treatment to 28 days. Instead, the information obtained from our CAM blockade experiments focused on mechanisms of leukocyte infiltration after transplantation rather than therapy, something not previously evaluated by others.

In summary, we have provided evidence that immune effector cell trafficking to allogeneic valve leaflets after implantation appears to occur via $\alpha 4$ and/or $\beta 2$ integrin pathways. We have also demonstrated that continuous daily cyclosporine treatment of recipients can result in 
inhibition of allograft valve infiltration and structural failure.

The development of methods to prolong the durability of allograft valves would have enormous clinical implications, especially for young people. Our findings suggest that it may be possible to use recipient immune modulation to maintain viable allografts that would lead to lifelong valve function free of complications. This has been the goal of cardiac surgeons for the past 40 years. The therapeutic approaches we are proposing may not protect valve leaflets indefinitely from cellular loss but may reduce the immune infiltration observed early after implantation. It is possible that attenuating this immune attack may lead to better preservation of the valve structural elements and thus prolong the survival of a functional, if not cellular, allograft valve.

\section{References}

1. Ross DN. Homograft replacement of the aortic valve. Lancet. 1962;2:447.

2. Ross DN, Somerville J. Correction of pulmonary atresia with a homograft aortic valve. Lancet. 1966;2:1446-7.

3. Matsuki O, Robles A, Gibbs S, Bodnar E, Ross DN. Long-term performance of 555 aortic homografts in the aortic position. Ann Thorac Surg. 1988;46:187-91.

4. Clarke DR, Campbell DN, Hayward AR, Bishop DA. Degeneration of aortic valve allografts in young recipients. J Thorac Cardiovasc Surg. 1993;105:934-42.

5. Zhao X, Green M, Frazer IH, Hogan P, O'Brien MF. Donor-specific immune response after aortic valve allografting in the rat. Ann Thorac Surg. 1994;57:1158-63.

6. Hogan P, Duplock L, Green M, Smith S, Gall KL, Frazer IH, et al. Human aortic allografts elicit a donor-specific immune response. $J$ Thorac Cardiovasc Surg. 1996;112:1260-7.

7. Hoekstra F, Knoop C, Vaessen L, Wassenaar C, Jutte N, Bos E, et al. Donor-specific cellular immune response against human cardiac valve allografts. J Thorac Cardiovasc Surg. 1996;112:281-6.

8. Rajani B, Mee RB, Ratcliff NB. Evidence for rejection of homograft cardiac valves in infants. J Thorac Cardiovasc Surg. 1998;115:111-7.

9. Lupinetti FM, Christy JP, King DM, Khatib HE, Thompson SA. Immunogenicity, antigenicity and endothelial viability of aortic valves preserved at $4^{\circ} \mathrm{C}$ in a nutrient medium. J Card Surg. 1991;6:454-61.

10. Moustapha A, Ross DB, Bittira B, Van-Velzen D, McAlister VC, Lannon CL, et al. Aortic valve grafts in the rat: evidence for rejection. J Thorac Cardiovasc Surg. 1997;114:891-902.

11. Khatib HE, Lupinetti FM. Antigenicity of fresh and cryopreserved rat valve allografts. Transplantation. 1990;49:765-7.

12. Shaddy RE, Tani LY, Sturtevant JE, Lambert LM, McGough EC. Effects of homograft blood type and anatomic type on stenosis, regurgitation and calcium in homografts in the pulmonary position. Am J Cardiol. 1992;70:392-3.

13. Yankah AC, Wottge H, Muller-Ruchholtz W. Short-course cyclosporin A therapy for definite allograft valve survival: immunosuppression in allograft valve operations. Ann Thorac Surg. 1995;60:S146-50.

14. Légaré JF, Lee TDG, Creaser K, Ross DB. T lymphocytes are responsible for allograft aortic valve failure in rat. Ann Thorac Surg. 2000;70:1238-45.

15. Rodriguez-Iturbe B. Cellular adhesion molecules in transplantation. Transplant Proc. 1996;28:3285-9.

16. Mulligan MS, Tsai TT, Kneebone JM, Ward PA, Lupinetti FM. Effects of preservation techniques on in vivo expression of adhesion molecules by aortic valve allografts. J Thorac Cardiovasc Surg. 1994;107:717-23.

17. Briscoe DM, Schoen FJ, Rice GE, Bevilacqua MP, Ganz P, Pober JS, et al. Induced expression of endothelial-leukocyte adhesion molecules in human cardiac allografts. Transplantation. 1991;51:537-9.

18. Olfert FD, Cross BM, McWilliam AA, editors. Guide to the care and use of experimental animals. Canadian Council of Animal Care, Guide. Vol 1, 2nd ed, 1993.

19. Yankah AC, Wottge HU, Muller-Ruchholtz W. Antigenicity and fate of cellular components of heart valve allografts. In: Yankah AC, Hetzer R, Yacoub MH, editors. Cardiac valve allografts 1962-87. Current concepts on the use of aortic and pulmonary allografts for heart valve substitutes. Darmstadt: Steinkopff Verlag; 1988. p. 77-87.

20. Ross DB, Hamilton GR, Wright JR, Lee TD. Homograft valve failure in children. J Thorac Cardiovasc Surg. 1999;117:1044-5.

21. Issekutz TB, Wykretowicz A. Effect of a new monoclonal antibody, TA-2, that inhibits lymphocyte adherence to cytokine stimulated endothelium in the rat. J Immunol. 1991;147:109-16.

22. Tamatami T, Kotani M, Miyasaka M. Characterization of the rat leukocyte integrin, CD11/CD18, by the use of LFA-1 subunit-specific monoclonal antibodies. Eur J Immunol. 1991;21:627-33.

23. Issekutz AC, Ayer L, Miyasaka M, Issekutz TB. Treatment of established adjuvant arthritis in rats with monoclonal antibody to CD18 and very late antigen-4 integrins suppresses neutrophil and T-lymphocyte migration to the joints and improves clinical disease. Immunology. 1996;88:569-76.

24. Li XC, Miyasaka M, Issekutz TB. Blood monocyte migration to acute lung inflammation involves both CD11/CD18 and very late activation antigen-4-dependent and independent pathways. J Immunol. 1998;161:6258-64.

25. Hilbert SL, Luna RE, Zhang J, Wang Y, Hopkins RA, Yu ZX, et al. Allograft heart valves: the role of apoptosis-mediated cell loss. $J$ Thorac Cardiovasc Surg. 1998;117:454-62.

26. Stepkowski SM, Kahan BD. Rapamycin and cyclosporine synergistically prolong heart and kidney allograft survival. Transplant Proc. 1991;23:3262-4

27. Mirelli M, Stella A, Faggioli GL, Scolari MP, Iannelli S, Freyrie A, et al. Immune response following fresh homograft replacement for aortoiliac graft infection, Eur J Endovasc Surg. 1999;18:424-9.

28. Springer TA. Adhesion receptors of the immune system. Nature. 1990;346:425-34.

29. Horimoto $H$, Ito $T$, Hayashi $T$, Miyasaka $M$, Nozawa $M$. Transplantation tolerance by a combined therapy with sulfatide, antiLFA-1/ICAM-1 monoclonal antibodies and FK06 in rat cardiac transplantation. Transplant Int. 1998;11(Suppl 1):S310-2.

30. Takada M, Nadeau K, Shaw GD, Marquette KA, Tilney NL. The cytokine-adhesion molecule cascade in ischemia/reperfusion injury of the rat kidney. J Clin Invest. 1997;99:2682-90.

31. Paul LC, Davidoff A, Benedicksson H, Issekutz TB. The efficacy of LFA-1 and VLA-4 antibody treatment in rat vascularized cardiac allograft rejection. Transplantation. 1993;55:1196-9. 